\title{
Correction to: Assessing size of pituitary adenomas: a comparison of qualitative and quantitative methods on MR
}

\author{
Benjamin M. Davies ${ }^{1} \cdot$ Elizabeth Carr $^{2} \cdot$ Calvin Soh $^{3} \cdot$ Kanna K. Gnanalingham ${ }^{1,3}$
}

Published online: 26 April 2018

(C) Springer-Verlag GmbH Austria, part of Springer Nature 2018

\section{Correction to: Acta Neurochir (2016) 158:677-683 \\ https://doi.org/10.1007/s00701-015-2699-7}

Unfortunately, it has come to our attention that there is a typographical error within the text.

We have incorrectly described the ellipsoid equation as being calculated using maximal diameters. It is in fact calculated using half the maximal diameter, i.e. the maximal radii. The diameter is initially recorded on the MRI images (as per Fig. 1), as the lesions do not have a defined midpoint.

This error is only within the text and the reported data is correct. This can be best appreciated by the close relationship between the volumetric and ellipsoid volumes. Use of the diameter would have led to an 8-fold increase in the calculated volume and clear disagreement.

Please find below the required amendments:

In paragraph 5, Page 2.
The online version of the original article can be found at https://doi.org/ 10.1007/s00701-015-2699-7

Kanna K. Gnanalingham

kanna.gnanalingham@srft.nhs.uk

1 Department of Neurosurgery, Greater Manchester Neurosciences Centre, Salford Royal Foundation Trust, Stott Lane, Salford, Manchester M6 8HD, UK

2 Manchester Academic Health Sciences Centre, University of Manchester, Manchester, UK

3 Department of Neuroradiology, Greater Manchester Neurosciences Centre, Salford Royal Foundation Trust, Stott Lane, Salford, Manchester M6 8HD, UK

\section{Current Text.}

Ellipsoid volume was calculated using the formula $4 / 3$ $\pi(a . b . c)$, where $a, b$ and $\mathrm{c}$ are the maximal orthogonal diameters in each dimension.

Should be:

Ellipsoid volume was calculated using the formula $4 / 3$ $\pi($ a.b.c), where $\mathrm{a}, \mathrm{b}$ and $\mathrm{c}$ are half the maximal orthogonal diameters in each dimension (i.e. maximal radii).

In Fig. 1.

Current Text.

$\mathrm{A} / \mathrm{B} / \mathrm{C}$ maximal diameters [should bisect midpoint] in each dimension $(\mathrm{x} / \mathrm{y} / \mathrm{z})$.

Should be:

$\mathrm{A} / \mathrm{B} / \mathrm{C}$ maximal diameters [should bisect midpoint] in each dimension $(x / y / z)$. These are then halved to provide the maximal radii $\mathrm{a} / \mathrm{b} / \mathrm{c}$ for the ellipsoid equation. 
A

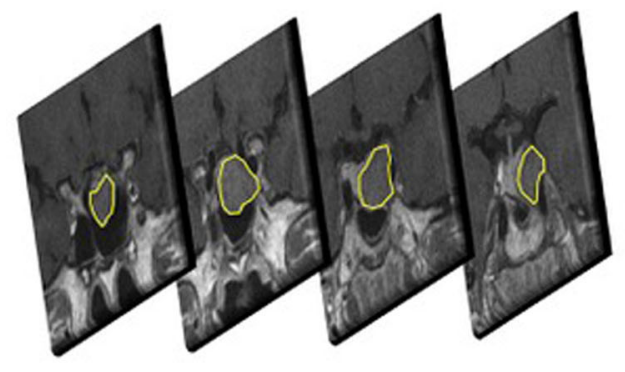

Segment width is the

slice thickness

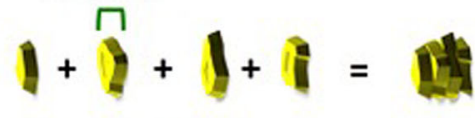

Volume estimation by Perimeter method

B
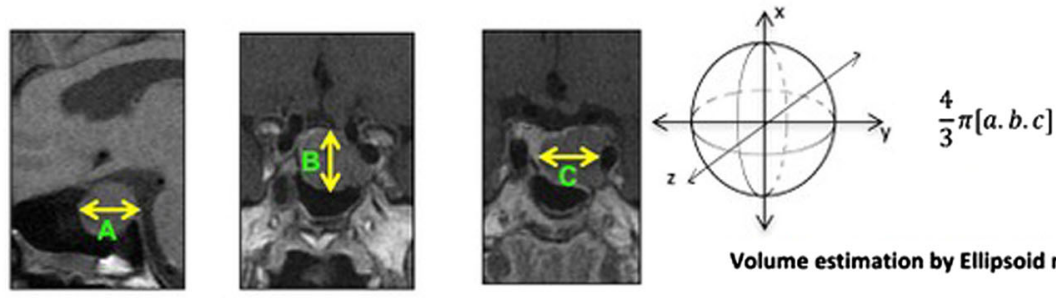

Volume estimation by Ellipsoid method

$\mathrm{A} / \mathrm{B} / \mathrm{C}$ maximal diameters [should bisect midpoint] in each dimension $(x / y / z)$. These are then halved to provide the maximal radii $\mathrm{a} / \mathrm{b} / \mathrm{c}$ for the ellipsoid equation.

Fig. 1 Dummy 